\title{
ATUAÇÃO DO ENFERMEIRO EM ONCOLOGIA NA PERSPECTIVA DA GENÉTICA E GENÔMICA
}

\author{
Milena Flória-Santos ${ }^{1}$, Erika Maria Monteiro Santos², Lucila Castanheira Nascimento ${ }^{3}$, Gabriela Pereira-da- \\ Silva ${ }^{4}$, Beatriz Rossetti Ferreira ${ }^{5}$, Diego Oliveira Miranda ${ }^{6}$, Luis Carlos Lopes-Júnior ${ }^{7}$, Patrícia da Silva Pinto
}

${ }^{1}$ Doutora em Ciências. Professora do Departamento de Enfermagem Materno-Infantil e Saúde Pública da Escola de Enfermagem de Ribeirão Preto (EERP) da Universidade de São Paulo (USP). São Paulo, Brasil. E-mail: milena@usp.br

${ }^{2}$ Doutora em Ciências. Pesquisadora do Hospital do Câncer A.C. Camargo. São Paulo, Brasil. E-mail: erikammsantos@gmail. com

${ }^{3}$ Doutora em Enfermagem. Professora do Departamento de Enfermagem Materno-Infantil e Saúde Pública da EERP/USP. São Paulo, Brasil. E-mail: lucila@eerp.usp.br

${ }^{4}$ Doutora em Ciências. Professora do Departamento de Enfermagem Materno-Infantil e Saúde Pública da EERP/USP. São Paulo, Brasil. E-mail: gbisson@eerp.usp.br

${ }^{5}$ Doutora em Ciências. Professora do Departamento de Enfermagem Materno-Infantil e Saúde Pública da EERP/USP. São Paulo, Brasil. E-mail: brferrei@usp.br

${ }^{6}$ Doutorando do Programa de Pós-Graduação em Saúde Pública da EERP/USP. São Paulo, Brasil. E-mail: imuno@usp.br

${ }^{7}$ Mestrando do Programa de Pós-Graduação em Saúde Pública EERP/USP. São Paulo, Brasil. E-mail: luisgen@usp.br

${ }^{8}$ Enfermeira do Hospital do Câncer de Ribeirão Preto, Fundação SOBECCan. São Paulo, Brasil. E-mail: paty_sill@hotmail.com

RESUMO: Este artigo tem como objetivo refletir sobre a atuação do enfermeiro em oncologia, sob a perspectiva da genética e da genômica, e sobre seu papel como membro integrante da equipe multiprofissional e interdisciplinar de aconselhamento genético oncológico. Trata-se de uma reflexão, fruto de leitura minuciosa da literatura da área, acrescida da experiência dos autores e discussões em grupo de pesquisa. No transcorrer desse trabalho, foi possível constatar que o enfermeiro precisa considerar o cuidado de saúde baseado em genômica e apropriar-se de competências essenciais. Essas competências abrangem a habilidade de mobilizar recursos genômicos na coleta da história familiar e nas orientações sobre testes genéticos a famílias em risco para síndromes neoplásicas hereditárias. O profissional de enfermagem pode atuar como referência para os demais membros da equipe de saúde, com potencial para integrar seus conhecimentos no cuidado, no ensino e em pesquisas em oncologia, sob a ótica da genética e da genômica.

DESCRITORES: Enfermagem. Oncologia. Genômica.

\section{ONCOLOGY NURSING PRACTICE FROM THE PERSPECTIVE OF GENETICS AND GENOMICS}

\begin{abstract}
This study aimed to reflect on oncology nurses' practice from the perspective of genetics and genomics, and their role as a member of the multiprofessional and interdisciplinary cancer genetics counseling team. This reflection is a result of the detailed reading of literature in the area, increased by the authors' experience and research group discussions. In the course of this work, it was verified that the nurse needs to consider genomic-based health care and incorporates essential competencies. These competencies include the ability to mobilize genomic resources in the family history assessment and in the guidelines on genetic testing for families at risk for hereditary neoplastic syndromes. The nursing staff may act as a reference for other members of the health team, with the potential to integrate their knowledge on care, teaching and research in oncology from the viewpoint of genetics and genomics.
\end{abstract}

DESCRIPTORS: Nursing. Oncology. Genomics.

\section{PRÁCTICA DE LO ENFERMERO EN ONCOLOGÍA EN LA PERSPECTIVA DE LA GENÉTICA Y GENÓMICA}

RESUMEN: Este estudio objetivó reflexionar sobre la práctica del enfermero en oncología en la perspectiva de la genética y genómica, y su papel como miembro del equipo multiprofesional e interdisciplinario del asesoriamento genético oncológico. Esta reflexión es resultado de lectura atenta de la literatura, además de la experiencia de los autores y discusiones del grupo de investigación. En el curso de este trabajo, fue posible constatar que el enfermero debe tener en cuenta el cuidado de salud basado en genómica y se apropiar de competencias esenciales. Estas competencias incluyen habilidad de movilizar recursos genómicos en la colecta de la historia familiar y orientaciones sobre testes genéticos para familias en riesgo de síndromes neoplásicas hereditarias. El profesional de enfermería puede actuar como referencia para los demás miembros del equipo de salud, con posibilidad de integrar sus conocimientos en asistencia, enseñanza e investigación en oncología, desde el punto de vista de la genética y genómica.

DESCRIPTORES: Enfermería. Oncología. Genómica. 


\section{INTRODUÇÃO}

Do ponto de vista fisiopatológico, as neoplasias malignas possuem bases genéticas e moleculares e podem ser reconhecidas como agravos genéticos causados por instabilidade genômica. ${ }^{1-2}$ Genômica, termo utilizado pela primeira vez por McKusick e Ruddle, ${ }^{3}$ é o estudo de todos os genes do genoma humano em conjunto, incluindo suas interações entre si e com o meio ambiente, compreendendo fatores físicos, psicossociais, culturais e suas implicações para o cuidado em saúde e de enfermagem. ${ }^{4-5}$

A genômica aplicada à saúde reflete as implicações do Projeto Genoma Humano na prática clínica e na personalização do cuidado. ${ }^{6}$ Essas implicações têm modificado o paradigma do cuidado em saúde, a classificação das doenças, o tratamento e o manejo de sintomas. Mediante o mapeamento do genoma humano, os modelos tradicionais de promoção da saúde, prevenção de agravos e produção de novos padrões de prática profissional estão se transformando, especialmente na área da oncologia. ${ }^{6-8}$

Com base nesses pressupostos, o presente artigo objetiva apresentar uma reflexão sobre a atuação do enfermeiro em oncologia, na perspectiva da genética e da genômica, e sobre seu papel enquanto membro integrante da equipe multiprofissional e interdisciplinar de aconselhamento genético em câncer. Essa reflexão é fruto de uma leitura minuciosa da literatura da área, acrescida da experiência dos autores e discussões realizadas pelo Grupo de Estudos e Pesquisas de Enfermagem em Genômica.

\section{ATUAÇÃO DOS ENFERMEIROS NA ERA GENÔMICA}

Há aproximadamente cinquenta anos, em consonância com as descobertas científicas que, consequentemente, transformam as práticas assistenciais à população, enfermeiros têm ministrado cuidados de saúde baseados em genômica, que incorporam o diagnóstico, a prevenção e a terapêutica com base nos genes. Sob esta ótica, as manifestações de saúde podem ser vistas como resultantes de combinações do genoma humano e de influências ambientais. ${ }^{9-11}$

Um importante marco histórico para a atuação dos profissionais de enfermagem foi a fundação da Sociedade Internacional dos Enfermeiros Geneticistas (International Society of Nurses in Genetics - ISONG), que atualmente conta com aproxima- damente 400 membros em 14 países, incluindo o Brasil. ${ }^{12}$ Essa organização é responsável por definir e estabelecer, internacionalmente, o escopo da prática profissional dos enfermeiros com bases na genética e na genômica. A ISONG determina as normas e diretrizes norteadoras do cuidado e estabelece níveis de competência profissional. ${ }^{5}$ No cenário nacional, a ação de enfermeiros norteia-se por essas diretrizes e tem sido semelhante à observada em outros países, sendo que as primeiras publicações brasileiras sobre a temática em questão ocorreram na década de $1980 .{ }^{10}$ Desde então, esse número vem aumentando gradativamente com a conquista de novos cenários de atuação. ${ }^{10}$

\section{Competências essenciais de enfermagem em genética e genômica}

Simultaneamente às publicações que divulgaram a conclusão do Projeto Genoma, o Instituto Nacional de Pesquisa do Genoma Humano, localizado nos Estados Unidos, publicou sua visão para o futuro da genômica, que ressaltava a necessidade de educação e capacitação da força de trabalho em saúde para ministrar cuidado de saúde na era genômica. ${ }^{4}$ Em resposta a essa demanda, enfermeiros que trabalham junto aos Institutos Nacionais de Saúde norte-americanos (National Institutes of Health - NIH) planejaram uma proposta para educação de enfermeiros e estabeleceram as "Competências Essenciais de Enfermagem e Diretrizes Curriculares para Genética e Genômica" (Quadro 1). ${ }^{13}$

Em 2008, a American Association of Colleges of Nurses, associação que determina o conteúdo curricular dos cursos de bacharelado em enfermagem norte-americanos, reformulou suas diretrizes, por considerar a complexidade da prática de enfermagem no século XXI. Esta associação, por sua vez, reformulou o documento "The Essentials of Baccalaureate Education for Professional Nursing Practice", o qual passou a recomendar que o enfermeiro: (a) seja educado nas relevantes ciências da genética, genômica, farmacogenética e farmacogenômica; (b) aprenda sobre o impacto social de tendências genéticas e genômicas nas políticas de saúde; (c) seja capaz de avaliar fatores protetores e preditivos, considerando os de origem genética, os quais influenciam a saúde de indivíduos, famílias, grupos, comunidades e populações; (d) levante a história de saúde, incluindo a história familiar, com riscos genéticos, para problemas de saúde atuais e futuros; (e) seja capaz de apreciar a evolução do conhecimento em genética e genômica, 
incluindo terapêuticas específicas para os clientes; (f) reconheça a relação da genética e da genômica com a saúde, prevenção, rastreamento, diagnóstico, prognóstico, seleção de tratamento, monitora- mento da eficácia do tratamento, utilizando-se do heredograma construído a partir de informações coletadas da história familiar, usando os símbolos e a terminologia padronizados para tal..$^{8,14}$

\section{Quadro 1 - Competências essenciais de enfermagem e diretrizes curriculares para genética e genômica}

\begin{tabular}{|c|c|}
\hline \multicolumn{2}{|r|}{ Competências } \\
\hline \multicolumn{2}{|r|}{ Responsabilidades profissionais } \\
\hline \multicolumn{2}{|c|}{$\begin{array}{l}\text { Reconhece as próprias atitudes e valores relacionados à genética e genômica que podem afetar o cuidado prestado } \\
\text { aos clientes. }\end{array}$} \\
\hline \multicolumn{2}{|c|}{ Advoga em favor dos clientes para o acesso aos serviços de genética/genômica, incluindo grupos de suporte. } \\
\hline \multicolumn{2}{|c|}{ Avalia sua competência regularmente, identificando áreas nas quais o desenvolvimento profissional pode ser benéfico. } \\
\hline \multicolumn{2}{|c|}{ Incorpora as tecnologias e informação em genética e genômica na prática de enfermagem. } \\
\hline \multicolumn{2}{|c|}{$\begin{array}{l}\text { Demonstra na prática a importância da informação genética e genômica personalizada de a } \\
\text { gião, nível educacional, conhecimento e idioma do cliente. }\end{array}$} \\
\hline \multicolumn{2}{|c|}{ Advoga pelo direito do cliente quanto à tomada de decisão autônoma e informada. } \\
\hline \multicolumn{2}{|c|}{ Prática profissional } \\
\hline \multirow{8}{*}{ Avaliação de enfermagem } & $\begin{array}{l}\text { Demonstra compreensão da relação da genética/genômica na saúde, prevenção, } \\
\text { rastreamento, diagnóstico, prognóstico, seleção do tratamento e monitorização da } \\
\text { efetividade do tratamento. }\end{array}$ \\
\hline & Demonstra habilidade em identificar história familiar com, no mínimo três gerações. \\
\hline & $\begin{array}{l}\text { Constrói heredograma da história familiar utilizando terminologia e símbolos ade- } \\
\text { quados. }\end{array}$ \\
\hline & $\begin{array}{l}\text { Coleta história pessoal, de saúde e desenvolvimento que consideram riscos gené- } \\
\text { ticos, ambientais e genômicos. }\end{array}$ \\
\hline & $\begin{array}{l}\text { Conduz avaliação de saúde e física que incorpora conhecimento sobre fatores de } \\
\text { risco genéticos, ambientais e genômicos. }\end{array}$ \\
\hline & Analisa criticamente a história física e de saúde. \\
\hline & $\begin{array}{l}\text { Avalia conhecimentos, percepções e respostas do cliente às informações genética } \\
\text { e genômica. }\end{array}$ \\
\hline & Desenvolve um plano de cuidado que incorpora a informação genética e genômica. \\
\hline \multirow{4}{*}{ Identificação } & $\begin{array}{l}\text { Identifica clientes que podem se beneficiar de informação genética/genômica espe- } \\
\text { cífica baseada na avaliação. }\end{array}$ \\
\hline & $\begin{array}{l}\text { Identifica informação correta, de credibilidade e atualizada sobre recursos e servi- } \\
\text { ços para os clientes. }\end{array}$ \\
\hline & $\begin{array}{l}\text { Identifica aspectos éticos, culturais, religiosos, legais e sociais relacionados à infor- } \\
\text { mação e tecnologia genética/genômica. }\end{array}$ \\
\hline & $\begin{array}{l}\text { Identifica fatores que cerceiam o direito dos clientes à tomada de decisão autôno- } \\
\text { ma e informada, e à ação voluntária. }\end{array}$ \\
\hline Atividades de encaminhamento & Facilita o encaminhamento para serviços especializados. \\
\hline \multirow{9}{*}{$\begin{array}{l}\text { Fornecimento de cuidado, edu- } \\
\text { cação e suporte }\end{array}$} & Fornece aos clientes interpretação da informação genética/genômica. \\
\hline & $\begin{array}{l}\text { Fornece aos clientes informação adequada, apropriada e atualizada sobre recur- } \\
\text { sos, serviços e tecnologia que facilitem a decisão informada. }\end{array}$ \\
\hline & $\begin{array}{l}\text { Considera a influência de fatores genéticos/genômicos nos fatores de risco am- } \\
\text { biental e pessoal. }\end{array}$ \\
\hline & Incorpora o conhecimento sobre os fatores de risco genético/genômico. \\
\hline & $\begin{array}{l}\text { Usa intervenções baseadas no conhecimento genético/genômico para melhorar o } \\
\text { resultado dos clientes. }\end{array}$ \\
\hline & Colabora com outros profissionais no fornecimento do cuidado genômico. \\
\hline & $\begin{array}{l}\text { Colabora com o sistema de saúde para permitir o pagamento dos serviços genô- } \\
\text { micos. }\end{array}$ \\
\hline & Realiza intervenções apropriadas às necessidades dos clientes. \\
\hline & $\begin{array}{l}\text { Avalia o impacto e a efetividade da informação, tecnologia, intervenções e trata- } \\
\text { mento genético/genômico sobre o cliente. }\end{array}$ \\
\hline
\end{tabular}

Fonte: Jenkins J, Calzone KA. ${ }^{13}$ 


\section{Interfaces entre o preparo acadêmico, níveis de atuação profissional e o cuidado de saúde baseado em genômica}

A enfermagem em genética e genômica é definida como a proteção, promoção e otimização da saúde; prevenção da doença e lesão; alívio do sofrimento por meio do diagnóstico das respostas humanas; e defesa, de forma pró-ativa, dos direitos de indivíduos, famílias e comunidades sob o cuidado genômico. ${ }^{5}$ Para que atue de forma a considerar essa definição, o papel e as competências do enfermeiro são determinados de acordo com o seu nível educacional e a complexidade de sua atuação na prática clínica. Os dois níveis de atuação propostos, de acordo com a formação acadêmica generalista ou especialista, são, respectivamente, o nível básico e o avançado e ambos incluem a aplicação da genética e da genômica na avaliação, no diagnóstico e nas intervenções de enfermagem. Entretanto, esses níveis diferenciam-se conforme a profundidade e abrangência do conhecimento, as habilidades, experiência profissional e o preparo formal para atuação clínica. ${ }^{5,9,12}$ Ressalta-se que, no Brasil, os níveis de competência requeridos para a prática são considerados em consonância com a Lei do Exercício Profissional de Enfermagem e já receberam reconhecimento formal. ${ }^{10}$

Atualmente, mesmo frente a essas novas abordagens do cuidar, muitos profissionais de saúde ainda consideram a genética apenas como uma especialidade médica e não como parte integrante de sua prática cotidiana. ${ }^{12}$ No entanto, a crescente importância atribuída ao conhecimento da história familiar e do perfil genético e genômico dos indivíduos e de suas famílias, terá um grande impacto na medicina preventiva nos anos vindouros, não apenas na oncologia, mas em todas as especialidades na área da saúde. ${ }^{7,12}$ Logo, a ênfase necessária à formação profissional com base em genômica se tornará um requisito importante à medida que a genética passe a integrar o cuidado de rotina, deixando de ser exclusivamente uma área de especialização. ${ }^{6-7,9}$

\section{INTERVENÇÕES DE ENFERMAGEM NA AVALIAÇÃO DE RISCO E NO ACONSE- LHAMENTO GENÉTICO EM CÂNCER}

Em meados da década de 1990, foram identificadas mutações em genes raros, que poderiam predispor seus portadores a um risco aumentado para neoplasias malignas. ${ }^{1-2}$ Nessa ocasião, a Socie- dade Americana de Oncologia Clínica propôs, pela primeira vez, recomendações para a realização de testes genéticos, que se tornaram parte do cuidado oncológico ministrado a clientes com neoplasias de mama, ovário, cólon, estômago, útero, tireóide e outros sítios primários. ${ }^{2}$ A partir de então, indivíduos com história familiar desses e outros tumores têm procurado, ou são referidos, a serviços especializados de genética, com a finalidade de realizar avaliação de risco e testes genéticos, quando existe a probabilidade de serem encontradas mutações gênicas de predisposição ao câncer., ${ }^{2,12}$

À medida que o público tem maior acesso a informações sobre a importância da genética no desenvolvimento do câncer, enfermeiros que trabalham com pacientes oncológicos devem estar preparados para atender às novas demandas de cuidado. ${ }^{12,15}$ Várias sociedades de profissionais de enfermagem nas áreas de oncologia, genética e genômica têm publicado documentos determinando as funções do enfermeiro na avaliação de risco e no aconselhamento genético oncológico. Essas funções podem ser divididas em atividades clínicas (assistenciais), educacionais, organizacionais (consultor, coordenador e administrador), e de pesquisa. ${ }^{15}$ Para o desenvolvimento de tais atividades foi proposta a sistematização da assistência por meio da aplicação do processo de enfermagem em cada etapa da avaliação de risco e aconselhamento genético, incluindo as etapas de: avaliação inicial, diagnóstico, estabelecimento do plano de cuidados, intervenção e avaliação dos resultados, conforme preconizado pela ISONG. ${ }^{5}$

\section{Ações educativas}

A educação é um dos pilares do processo de aconselhamento genético em câncer e modelos para essa atividade incluem sessões em grupo e/ ou individuais. ${ }^{2,15}$ As ações educativas precisam ser dinâmicas e interativas, realizadas por meio de estratégias pedagógicas participativas adequadas à educação de adultos e que possam ir ao encontro de suas necessidades de saúde. Pressupõe-se que essas ações sejam traçadas de acordo com a capacidade de compreensão dos sujeitos, seu nível educacional, formas de percepção de risco, história pessoal e familiar de neoplasias, com consideração às suas crenças e hábitos culturais. ${ }^{11,15}$ Recomendase que os principais tópicos a serem abordados incluam conceitos básicos de genética e genômica, o câncer como doença genética e hereditária, aspectos etiológicos das neoplasias, fatores de risco 
ambientais, estratégias de prevenção e diagnóstico precoce. ${ }^{2,15}$ Durante essas sessões, podem ser aplicados questionários de avaliação diagnóstica, para obtenção de dados fundamentais da história pessoal e familiar desses indivíduos, assim como fatores de exposição ambiental e aspectos do estilo de vida. Esses questionários podem ser respondidos em casa com a finalidade de estimular um maior contato entre os familiares e a obtenção de documentos médicos que possam validar a história familiar previamente reportada de forma que as informações coletadas sejam o mais fidedignas possível. ${ }^{2,11,15}$ Os principais objetivos dessas práticas educativas visam ampliar o conhecimento dos clientes sobre os aspectos genômicos e hereditários das neoplasias, elucidar sobre a necessidade de futuras investigações genéticas dos indivíduos em questão, esclarecer acerca de concepções errôneas sobre oncogenética e oferecer condições para a tomada de decisões informadas referentes às opções de tratamento, seguimento e testes genéticos. ${ }^{2,11,15}$

\section{Aconselhamento genético em câncer}

O aconselhamento genético surgiu na literatura de enfermagem no início da década de 1960, enfatizando como principal responsabilidade dos enfermeiros, junto à equipe multiprofissional, $\mathrm{o}$ suporte psicossocial e o acompanhamento dos casos. ${ }^{16}$ Tornou-se parte da linguagem sistematizada de enfermagem quando foi incluído na Classificação das Intervenções de Enfermagem (Nursing Interventions Classification-NIC), por meio da qual foi definido como um processo interativo de ajuda, focado na assistência ao indivíduo, família ou grupo, que apresenta ou possui risco para desenvolver, ou, ainda, transmitir um defeito congênito ou uma condição genética. ${ }^{16} \mathrm{O}$ aconselhamento genético também é definido como um processo de comunicação ou educação, por meio do qual o sujeito e os membros de sua família recebem informações sobre a natureza, os benefícios, os riscos e o significado do resultado de testes genéticos. ${ }^{2,11,16}$ Durante o processo de aconselhamento, também é oferecido apoio aos clientes, para que possam lidar com as implicações referentes aos possíveis resultados dos testes de predisposição ao câncer. Os indivíduos que realizam esses exames precisam receber as orientações necessárias para tomar decisões informadas sobre sua saúde e para consentir de forma voluntária e consciente, mediante a assinatura do termo de consentimento livre e esclarecido, antes de coletar o sangue para as análises genéticas. ${ }^{2,11,16-17}$

\section{Consultas de enfermagem}

Os enfermeiros são profissionais que, usualmente, têm uma interação bastante próxima e direta com os clientes e, geralmente, são os primeiros a terem contato com esses indivíduos nos serviços de saúde. Durante a consulta de enfermagem, procura-se ir além do biológico, por meio do levantamento das necessidades de saúde do sujeito em seu contexto familiar, as quais podem ser supridas com intervenções de enfermagem, ou atendidas mediante encaminhamento a outros profissionais da equipe multiprofissional de aconselhamento genético. ${ }^{11,16} \mathrm{~A}$ entrevista e o exame físico são instrumentos utilizados na avaliação de enfermagem. Segundo a ISONG, os dados a serem coletados durante a mesma incluem as expectativas do cliente; sua história pessoal e familiar de saúde; dados sobre a dinâmica e estrutura familiar; informações sobre suas práticas de saúde; fatores ambientais e econômicos que podem afetar sua saúde; padrões de adaptação e enfrentamento de doenças; seus sistemas de apoio; seus valores e crenças; assim como seu conhecimento sobre a influência da genética e da genômica na etiologia de sua patologia. ${ }^{5}$

\section{Coleta da história familiar e avaliação de risco}

Dentre os itens que compõem a avaliação, a história familiar de câncer é o que merece o maior destaque, uma vez que a identificação de muitas síndromes neoplásicas hereditárias ocorre por meio de uma história devidamente coletada e validada. ${ }^{1-2}$ Algumas habilidades são importantes para a obtenção da história familiar, tais como: conhecimentos de genética básica, capacidade de comunicação, habilidade para desenvolver relacionamentos interpessoais empáticos, persistência e conhecimento dos aspectos éticos e legais que podem surgir. ${ }^{15}$

Ao coletar e interpretar os dados da história familiar, o enfermeiro precisa ter conhecimentos de marcadores clínicos que indicam suscetibilidade herdada ao câncer, denominados como "bandeiras vermelhas", que incluem: (a) idade jovem ao diagnóstico (em geral inferior a 50 anos); (b) tumores bilaterais em órgãos pares; (c) presença de múltiplos tumores distintos em um mesmo órgão; (d) múltiplos tumores primários no mesmo indivíduo; (e) presença de tumores em dois ou mais parentes de primeiro ou segundo grau; (f) "constelação" de tumores em um sujeito ou sua família, reconhecidos como parte de uma síndro- 
me neoplásica hereditária já descrita na literatura; e (g) associações de câncer com lesões benignas., ${ }^{1,15}$

A coleta de dados deve ser realizada sistematicamente pelo profissional de saúde, junto ao indivíduo que está passando pela consulta, isto é, o probando ou caso-índice. ${ }^{15}$ Se ele for afetado por câncer, é importante que seja relatado o sítio primário de ocorrência da neoplasia, com comprovação por meio de exames anatomopatológicos que apresentem dados sobre o tipo histológico do tumor e a idade ao diagnóstico da doença. ${ }^{1}$ Para que possa ser identificado um padrão de herança genética, preconiza-se que a história familiar englobe dados de no mínimo três gerações. ${ }^{11}$ Inicia-se perguntando sobre a história de saúde dos parentes de primeiro grau, tendo sempre como referência as "bandeiras vermelhas". Prossegue-se com a avaliação da história de parentes de segundo e terceiro graus. ${ }^{1}$ Tanto o ramo materno quanto o paterno devem ser investigados e, em caso de falecimento, devem ser mencionadas a idade e a causa do óbito. Devido ao efeito fundador observado em diversas doenças genéticas, a origem étnica e racial de cada ramo da família deve fazer parte dos dados coletados. Informações sobre o estilo de vida e exposição ambiental a carcinógenos têm que ser investigadas em relação a todos os membros da família. Além disso, todos os dados obtidos precisam ser comprovados por meio de prontuários ou relatórios médicos, resultados de exames anatomopatológicos e atestados de óbito, pois somente deste modo será possível uma avaliação fidedigna, conduzindo a um diagnóstico preciso. $^{1,15}$

$\mathrm{Na}$ ausência de testes genéticos disponíveis para detectar a suscetibilidade a determinados tipos de câncer, a história familiar é um importante instrumento genômico, efetivo e de baixo custo, para identificar categorias de risco e indivíduos que possam estar mais predispostos a desenvolver neoplasias. ${ }^{15} \mathrm{~A}$ partir da história familiar relatada pelo cliente, o enfermeiro pode construir o heredograma, que é a representação dessa história utilizando-se de símbolos padronizados para tal. O heredograma facilita a visualização da história familiar, a identificação do padrão de herança genética e a avaliação dos indivíduos sob risco, o que facilita o acesso a esses dados, durante os atendimentos da equipe multiprofissional de aconselhamento genético oncológico. ${ }^{1,15}$

A história pessoal e familiar, assim como o heredograma, são recursos bastante úteis na estimativa de risco para o desenvolvimento de câncer.
O conhecimento do grau de risco é importante para a tomada de decisões quanto à realização ou não do teste genético, indicação de condutas de rastreamento clínico e utilização de medidas de quimioprevenção. ${ }^{2}$ Vários métodos e modelos estatísticos têm sido propostos para quantificar o risco associado à história familiar de câncer. ${ }^{2}$ Uma vez realizado o diagnóstico e determinado o risco de desenvolvimento de câncer, de acordo com as características clínicas da família, a equipe de saúde orienta o probando quanto à indicação de testes genéticos preditivos, sobre seu seguimento individualizado e de seus familiares, assim como quanto ao programa de prevenção e rastreamento específicos para seu caso e para sua família. ${ }^{17}$

\section{Testes genéticos}

Quando os clientes optam por realizar o teste genético, o enfermeiro necessita ampliar suas orientações e incluir em suas consultas tópicos que precisam ser considerados, tais como, suas motivações para a realização do teste, como irá trabalhar com o resultado obtido e seus padrões de comunicação com familiares. ${ }^{17} \mathrm{O}$ consentimento do cliente em submeter-se ao teste genético tem que ser voluntário, porém o enfermeiro pode participar como facilitador desse processo de tomada de decisão, oferecendo apoio psicossocial na intenção de auxiliá-lo a compreender os riscos, benefícios e limitações dos testes, seus potenciais resultados, sensibilidade e especificidade dos exames, assim como o direito de recusar-se a receber o resultado, ou mesmo de realizar o teste, sem quaisquer implicações para seu tratamento ou seguimento. Esses tópicos devem fazer parte do termo de consentimento livre e esclarecido, o qual, de acordo com normas éticas e legais, todo cliente deve assinar antes da realização de testes genéticos., ${ }^{2,17}$

A maioria dos serviços brasileiros de aconselhamento genético disponibiliza testes para as síndromes neoplásicas hereditárias prevalentes na população, como as síndromes de câncer de mama hereditário, nas quais os genes testados com maior frequência são os genes $B R C A 1$ e $B R C A 2$, e as síndromes de câncer colorretal e ginecológico, nas quais os genes de reparo MLH1, MSH2, MSH6, PMS1 e PMS2 podem ser pesquisados. ${ }^{1,2,17}$ Esses testes são realizados para detectar mutações germinativas herdadas em genes de alta penetrância, os quais são associados com o tipo de tumor observado nos indivíduos e famílias que buscam aconselhamento. ${ }^{2,17}$ Outras mutações com penetrância intermediária também têm sido 
reportadas em famílias com câncer de mama e de cólon hereditários, mas seu impacto na prática clínica ainda não está bem estabelecido. Essas mutações de penetrância alta e intermediária são consideradas raras e, mais comumente, a suscetibilidade herdada ao câncer é atribuída a um número de sequências variantes do material genético com baixa penetrância. A localização genômica de muitas dessas variações de baixa penetrância tem sido estabelecida por meio de estudos de associação em todo o genoma, os quais ainda não fazem parte das recomendações clínicas de rotina. No entanto, instituições privadas já oferecem esses exames, por meio de testes genéticos direto ao consumidor, cujo impacto potencial na população ainda é totalmente desconhecido., ${ }^{2,15}$

\section{Seguimento e retornos}

O seguimento dos clientes é um componente essencial do processo de aconselhamento genético. Todas as informações que recebem durante as consultas são bastante complexas, portanto o enfermeiro precisa acompanhar a evolução de seus clientes ao longo desse processo e avaliar o entendimento do aconselhamento. ${ }^{15}$ Os retornos e o acompanhamento são importantes para a atualização da história familiar, tanto como para reforçar comportamentos saudáveis em relação à prevenção do câncer e verificar a adesão aos programas de rastreamento e detecção precoce de futuras lesões. É ideal que, uma vez por ano, o enfermeiro entre em contato com as famílias para verificar alterações no histórico familiar. ${ }^{12,15}$

\section{POSSIBILIDADES E DESAFIOS}

Diante do exposto, o profissional de enfermagem, ao atuar em oncologia, pode aplicar seus conhecimentos para realizar a avaliação de risco para o desenvolvimento de neoplasias, com enfoque nos aspectos genéticos e genômicos. ${ }^{15}$ É essencial que essa avaliação seja parte integrante da sua rotina e inclua, especialmente, a coleta e registro da história familiar, facilitando o encaminhamento aos especialistas. O enfermeiro é o profissional que precisa reforçar as recomendações sobre o cuidado e as informações fornecidas pelos especialistas em genética, com competência para fornecer orientações, suporte e avaliar, constantemente, as respostas dos indivíduos ao cuidado recebido. ${ }^{12,17}$

A ISONG recomenda aos profissionais de enfermagem que queiram atuar em um nível avançado de prática profissional, na área da genética e da genômica, a realização de pós-graduação que compreenda essas temáticas, ou a oncologia., Mediante essa capacitação, o enfermeiro estará apto para realizar avaliação de risco detalhada, de forma personalizada, junto aos indivíduos e seus familiares, com a utilização de modelos estatísticos que compreendem algoritmos disponíveis para cálculo de probabilidades para manifestação da doença oncológica e para identificar possíveis portadores de mutações genéticas. ${ }^{2,15}$ Esse profissional pode discutir as implicações do teste genético e realizar o aconselhamento, atuando como referência para os demais colegas da equipe de enfermagem, podendo, também, participar e/ou conduzir pesquisas na área. ${ }^{12,15,17}$

Gradativamente, as novas tecnologias da medicina oncológica personalizada, estão permitindo a caracterização detalhada da biologia individual das neoplasias e dos sujeitos portadores das mesmas. ${ }^{2}$ As decisões terapêuticas que se baseiam nessa personalização têm compreendido a integração de complexas considerações clínico-patológicas, técnicas e socioeconômicas. ${ }^{2,6-7}$ A medicina personalizada envolve todos os profissionais de saúde e sinaliza para a necessidade de educação desses sujeitos sobre o significado e as implicações da informação genômica aplicada ao seu cotidiano profissional. ${ }^{2,6} \mathrm{O}$ crescente número de abordagens baseadas nos genes e o avanço tecnológico proporcionado pelo Projeto Genoma Humano estão levando à redefinição na patofisiologia, prevenção e terapêutica de diversas condições. Embora a enfermagem seja a maior força de trabalho, que ministra cuidados de saúde em todo o mundo, a maioria dos enfermeiros ainda não teve a iniciativa de confrontar-se com esses avanços, muitas vezes por déficit de conhecimento ou por dificuldades de acesso a fontes de informação atualizadas e contextualizadas à sua prática cotidiana. ${ }^{18}$ Os profissionais de enfermagem necessitam de programas de capacitação e educação permanente, pois, cada vez mais, ocuparão um papel central no planejamento e na execução do cuidado de saúde baseado em genômica.

\section{CONCLUSÃO}

Agora, mais do que nunca, é fundamental que os enfermeiros possam se apropriar das competências essenciais em genética e genômica, fato que deixa de ser uma opção e passa a ser imprescindível ao exercício da enfermagem no século XXI. É preciso avançar e assumir papéis de liderança nas iniciativas voltadas para a integra- 
ção dessas ciências ao cuidado oncológico, com foco no indivíduo e na sua família. Portanto, conclui-se que, o profissional de enfermagem pode atuar como referência para os demais membros da equipe de saúde, com potencial para aplicar seus conhecimentos na assistência, no ensino e na pesquisa oncológica, sob a ótica da genética e da genômica.

\section{REFERÊNCIAS}

1. Lindor NM, McMaster ML, Lindor CJ, Greene MH. Concise handbook of familial cancer susceptibility syndromes - second edition. J Natl Cancer Inst Monogr. 2008 Jul; 38):1-93.

2. Robson ME, Storm CD, Weitzel J, Wollins DS, Offit K. American Society of Clinical Oncology policy statement update: genetic and genomic testing for cancer susceptibility. J Clin Oncol. 2010 Jun; 28(5):893-901.

3. McKusick VA, Ruddle FH. Toward a complete map of the human genome. Genomics. 1987 Oct; 1(2):103-6.

4. Guttmacher AE, Collins FS. Welcome to the genomic era. N Engl J Med. 2003 Sep; 349(10):996-8.

5. International Society of Nurses in Genetics. American Nurses Association. Genetics/genomics nursing: scope and standards of practice. Silver Spring, Md: Nursesbooks.org; 2007.

6. Lea DH, Skirton H, Read CY, Williams JK. Implications for educating the next generation of nurses on genetics and genomics in the 21st century. J Nurs Scholarsh. 2011 Mar; 43(1):3-12.

7. Parkinson DR, Ziegler J. Educating for personalized medicine: a perspective from oncology. Clin Pharmacol Ther. 2009 Jul; 86(1):23-5.
8. Thompson HJ, Brooks MV. Genetics and genomics in nursing: evaluating essentials implementation. Nurse Educ Today. 2011 Aug; 31(6):623-7.

9. Jenkins J, Bednash G, Malone B. Bridging the gap between genomics discoveries and clinical care: nurse faculty are key. J Nurs Scholarsh. 2011 Mar; 43(1):1-2.

10. Floria-Santos M, Nascimento LC. Perspectivas históricas do projeto genoma e a evolução da enfermagem. Rev Bras Enferm. 2006 May-Jun; 59(3):358-61.

11. Jenkins JF, Lea DH. Nursing care in the genomic era: a case-based approach. Sudbury, Mass: Jones and Bartlett Publishers; 2005.

12. Calzone KA, Cashion A, Feetham S, Jenkins J, Prows CA, Williams JK, et al. Nurses transforming health care using genetics and genomics. Nurs Outlook. 2010 Jan; 58(1):26-35.

13. Jenkins J, Calzone KA. Establishing the essential nursing competencies for genetics and genomics. J Nurs Scholarsh. 2007 Mar; 39(1):10-6.

14. De Sevo MR. Genetics and genomics resources for nurses. J Nurs Educ. 2010 Aug; 49(8):470-4.

15. Jenkins J. Essential genetic and genomic nursing competencies for the oncology nurse. Semin Oncol Nurs. 2011 Feb; 27(1):64-71.

16. Craft-Rosenberg M, Denehy JA. Nursing interventions for infants, children, and families. Thousand Oaks (US): Sage Publications; 2001.

17. Bancroft EK. Genetic testing for cancer predisposition and implications for nursing practice: narrative review. J Adv Nurs. 2010 Apr; 66(4):710-37.

18. Flória-Santos M, Nascimento LC. Cuidado de enfermagem na era genômica: uma abordagem baseada em casos. Texto Contexto Enferm. 2005 Out-Dez; 14(4):616-8.
Correspondência: Milena Flória-Santos

Departamento de Enfermagem Materno-Infantil e Saúde

Pública

Escola de Enfermagem de Ribeirão Preto da Universidade de São Paulo

Av. Bandeirantes, 3900

14040-902 - Ribeirão Preto, SP, Brasil.

E-mail: milena@usp.br
Recebido: 03 de Agosto de 2011 Aprovação: 14 de Março de 2012 